\title{
Osmaniye İlinde Yerfıstığı Yetiştiriciliği ile İlgili Sorunların Saptanması
}

\author{
*Necmi IŞLER ${ }^{1} \quad$ Remzi GÖZÜYEŞíL² \\ ${ }^{1}$ Mustafa Kemal Üniversitesi, Ziraat Fakültesi, Tarla Bitkileri Bölümü, Hatay \\ ${ }^{2}$ Dörtyol Gıda, Tarım ve Hayvancılık İlçe Müdürlüğü, Hatay \\ *Sorumlu yazar e-posta (Corresponding author e-mail): nisler@mku.edu.tr
}

Öz

Türkiye'de yerfıstığı ekim alanının \%37'si, üretim miktarının ise \%40'ı (2011) Osmaniye ilinde gerçekleşmektedir. Osmaniye ilinde yerfıstığı üretimi yapan tarım işletmeleri incelenerek; sosyo ekonomik yapıları ve üretim teknikleri belirlenmiş, sorunları tespit edilerek, çözüm önerileri sunulmuştur. Ayrıca; yerfıstığı üretimiyle ilgili beklentilerin tespit edilerek, tarım politikalarının geliştirilmesinde katkıda bulunulması hedeflenmiştir. Bu araştırmanın materyalini, tesadüfi olarak seçilen toplam 100 yerfıstığı üreticisi ile yüz yüze anket yoluyla elde edilen bilgiler oluşturmaktadır. Bu yerfıstığı üreticileri Osmaniye Merkez, Kadirli, Düziçi ve Sumbas İlçelerinde bulunan toplam 20 köyden seçilmiştir. Anket çalışması Aralık 2012 - Şubat 2013 tarihleri arasında gerçekleştirilmiştir. Elde edilen bilgiler 2012 yılı üretim dönemine aittir. Anket sonuçlarına göre, incelenen işletmelerin ortalama işletme arazisi 128.14 da, yerfıstığı arazisi ise 52.85 da'dır. İşletmelerde 1. ürün olarak yetiştiriciliği yapılan yerfıstığı ekim alanı, toplam yerfıstığı ekim alanının \%70.71'ini oluşturmakta, 2. ürün yerfıstığı ekim alanı ise, toplam yerfıstığı ekim alanının \%29.29'unu oluşturmaktadır. İşletmelerin yaşadıkları en büyük sorunlar; gübre fiyatlarının yüksek olması, yerfıstığı fiyatının düşük olması, sulama maliyetlerinin yüksek olması ve yağışlar nedeniyle zamanında hasat yapılamaması olarak belirlenmiştir. Yerfıstığı üretiminde ortalama verim $323.70 \mathrm{~kg} / \mathrm{da}$, satış fiyatı ise ortalama 2.30 TL/kg olarak belirlenmiştir.

Anahtar Kelimeler: Üretim tekniği, yerfıstığı, anket, Osmaniye

\section{Inheritance of Coleoptile Length in Cross Populations of Some Modern Wheat Varieties and Landraces}

\begin{abstract}
$37 \%$ of the peanut production area in Turkey, $40 \%$ of the amount of production (2011) takes place in the province of Osmaniye. By examing the agricultural enterprises that producing peanut in osmaniye, socioeconomic structures and production techniques have been specified, problems were identified and solutions are presented. Besides expectations related to peanut production have been determined to contribute to the development of agricultural policy has been targeted. The material of this reserch is obtained by information of face to face questionnaire form with total of 100 randomly peanut producer. This peanut producers were selected from total 20 villages at Osmaniye Center, Kadirli, Düziçi and Sumbas Counties. This Survey was conducted between December 2012 and February 2013. The obtained information belongs to period of production for 2012. According to the results of survey, the average land of the examined enterprises is $128.14 \mathrm{da}$ and land for peanut is $52.85 \mathrm{da}$. In peanut producers; production area for the first product constitutes $70.71 \%$ of total area of peanut production, production area for the second product forms $29.29 \%$ of total area of peanut production. The defined biggest problems for enterprises faced are high fertilizer prices, low peanut price, high costs of irrigation and inability to timely harvesting due to rains. $323.70 \mathrm{~kg} / \mathrm{da}$ is an average yield in the production of peanuts and $2.30 \mathrm{TL} / \mathrm{kg}$ is an average selling price are determined.
\end{abstract}

Keywords: Production techniques, peanut, surveys, Osmaniye

\section{Giriş}

ürkiye'de 2012 yılında yerfıstığı ekim alanı 371.949 da, üretim ise 122.780 tondur. Aynı yıl, ülkedeki yerfıstığı ekim alanlarının \%93'üne sahip olan Akdeniz Bölgesi'nde toplam yerfıstığı

üretiminin \%92'ü gerçekleştirilmiştir. Ayrıca, yerfıstığı ekim alanının \%82'si Adana ve Osmaniye illerinin sınırları içerisinde bulunmakta ve yerfıstığı üretiminin $\% 85^{\prime} i$ bu iki ilde 
gerçekleştirilmektedir. Gaziantep ili 414 kg/da ile en yüksek verime sahip olan ildir. Bunu 410 $\mathrm{kg} / \mathrm{da}$ ile Isparta, $397 \mathrm{~kg} / \mathrm{da}$ ile Şırnak, 346 $\mathrm{kg} / \mathrm{da}$ ile Osmaniye ve $345 \mathrm{~kg} / \mathrm{da}$ ile Adana illeri izlemektedir. Adana ve Osmaniye illerinden daha yüksek verim elde edilmesi aldatıcı olmamalıdır. Zira verimi yüksek olan illerde ekim alanı yok denecek kadar azdır. Yerfıstığı yağlı tohumlu bitkiler ekim alanının yaklaşık \%3'ünü oluşturmaktadır (TÜIKK 2014).

Ülkemizde üretimi sınırlandıran faktörlerin başında mevcut çeşitlerin verim potansiyelinden çok, üretim tekniğindeki hata ve eksiklikler gelmektedir. Tarım sektöründe tarımsal girdi kullanımının yetersiz olması ve modern tarım tekniklerinin yeterince uygulanmıyor olması gibi sorunlar çözülmeden üretim artışı sağlamak ve rekabet edebilir bir tarım sektörü oluşturmak çok zor görünmektedir. Bütün tarımsal üreticilerin amacl; mevcut kaynaklarla, tekniğine uygun tarım yaparak üretimi artırmak olmalıdır. Bu amacı gerçekleştiren üretici kaynaklarını daha etkili kullanmıştır. Böylece kaynaklar etkin kullanılarak, verimlilik ve karlılık arttırımış olacak, gereksiz harcamalardan ve uygulamalardan kaçınılarak ağırlığı yurt dışından temin edilen ham madde ve tarımsal girdilerden tasarruf sağlanmış olacaktır. Anket çalışmaları ile elde edilen verilerden yola çıkarak yapılan değerlendirme neticesinde işletmelerin uyguladıkları tarım teknikleri, sorunları, beklentileri ve sosyo-ekonomik yapıları belirlenebilmektedir. Çıkan sonuçlardan belirlenen; üretim tekniklerindeki hatalar ve bunların giderilmesine dair öneriler, yaşanan sorunlara ait öneriler ve beklentilere yönelik politikalar üretilmesi işletmelerin verimliliğini ve gelirlerini artırmada etkili olacaktır. Bu çalışmada, yerfıstığı üreten işletmelerin yapısı incelenerek, üretim teknikleri, kaynak kullanım durumları, toprak işleme, gübreleme, ekim, sulama, hasat, kurutma, depolama ile pazarlama dönemleri ve yerfıstığı tarımında karşılaştıkları sorunlar gibi üretimde etkili olabilecek çeşitli faktörler belirlenerek işletmelerin yerfıstığı üretim yapısı ortaya konmuştur. Elde edilen verilerden faydalanılarak işletme bazında yerfıstığı yetiştiricilerinin; üretim teknikleri, karşılaştıkları sorunlar ve beklentileri belirlenmiş ve gerekli önerilerde bulunulmuştur. $\mathrm{Bu}$ çalışmanın amaçları aşağıdaki gibi özetlenebilir:

$\mathrm{Bu}$ çalışmanın başlıca amacı; Osmaniye ilinde yerfıstığı yetiştiren işletmelerin sosyo- ekonomik yapısı ve üretim tekniklerinin belirlenmesi, sorunlarının tespit edilerek, çözüm önerileri sunulmasıdır. Bununla birlikte diğer amaçlar; yerfıstığı üretimiyle ilgili beklentilerin tespit edilerek, tarım politikalarının geliştirilmesinde katkıda bulunulması ve Osmaniye ilinde yerfıstığı tarımının mevcut durumunun ortaya konulması şeklinde sıralanabilir.

\section{Materyal ve Yöntem}

$\mathrm{Bu}$ araştırmanın materyalini, araştırma alanındaki yerfıstığı yetiştiriciliği yapan tarım işletmelerinden yüz yüze anket uygulamaları yoluyla elde edilen bilgiler oluşturmaktadır. Anket çalışması Aralık 2012 - Şubat 2013 tarihleri arasında gerçekleştirilmiştir. Elde edilen bilgiler 2012 yılı üretim dönemine aittir. Araştırma ikincil verilerle desteklenmiştir. Bu amaçla GTHB Osmaniye İ Müdürlüğü kayıtlarından, TÜIK ve FAO istatistiksel verilerinden yararlanılmıştır. Ayrıca konu ile ilgili yurtiçi ve yurtdışında yapılmış çalışma bulgularından yararlanılmıştır.

Türkiye'de yerfıstığı ekim alanının \%37'sine sahip, üretim miktarının \%40'ını (2011) gerçekleştiren Osmaniye ili araştırma alanı olarak belirlenmiştir. Örnekleme çerçevesi oluşturmak için Çukurova bölgesinde özellikle üretimin önemli bir kısmını gerçekleştiren Osmaniye ilinde, GTHB İ Müdürlüğünden yoğun olarak yerfıstığı üretimi yapılan ilçe ve köylerde 2012 yılında ÇKS' ye kayıtlı çiftçi sayıları talep edilmiştir. GTHB Osmaniye î Müdürlüğünce verilen cevapta, 2012 yılında Osmaniye ilinde ÇKS' ye kayıtlı 1.227 çiftçinin olduğu ve bu kayıtlı çiftçilerin 1.207'sinin Kadirli, Osmaniye merkez, Düziçi ve Sumbas ilçelerinde yer aldığı belirtilmiştir. GTHB Osmaniye İl Müdürlüğü ile yapılan istişareler ve konu ile ilgili geçmiş çalışmalar dikkate alınarak araştırma amacına göre tarımsal üretim yapısı, iklim şartları ve uygulanan üretim teknikleri bakımından benzer özellik gösteren ve araştırma alanını temsil edebilecek dört ilçe ve 20 köy gayeli olarak seçilmiştir. Yörede farklı büyüklükteki arazilerde üretim yapan üreticilerden yeterli örnek alınması hedeflenerek belirlenen köylerden tesadüfi olarak seçilen 100 üreticiden oluşan örnek büyüklüğünün ana kitleyi temsil edeceği düşünülmüştür. Nitekim bir bölgede benzer özellikler taşıyan işletmelerden iyi seçilmiş 100 işletmeden oluşan örnek büyüklüğünün, tarımsal işletmecilik araştırmalarında genellikle yeterli görülmektedir (Yang 1964) 
Araştırma sonuçları değerlendirilirken işletmeler 3 gruba ayrılıışıtır. Bunlar; 1-25 da (birinci grup), 26-55 da (ikinci grup) ve 55 dekar ve üzeri (üçüncü grup) yerfıstığı ekim alanı genişlikleridir. Birinci grupta 39, ikinci grupta 30 ve üçüncü grupta 31 örnek sayısı olmak üzere toplam örnek sayısı 100 üretici olarak belirlenmiştir.

\section{Bulgular ve Tartışma}

Araştırmada işletme genişliği mülk arazi ile kiraya ve ortağa tutulan araziler toplamından oluşmuştur. Bu bölümde araştırma bölgesinde tespit edilen arazi varlığı, arazi tasarruf şekilleri ve ürün deseni konuları ortaya konulmuştur. İncelenen işletmelerin arazi büyüklükleri Çizelge 1 'de verilmiştir. Buna göre, toplam işletme arazisi ortalama 128.14 dekardır. En büyük arazi genişliği 228.29 da ile üçüncü grupta yer almakta ve bu işletmeler toplam işletme arazisinin $\% 55.32$ 'sini oluşturmaktadır.

Araştırma bölgesinde işletmeler ortalamasında toplam yerfıstığı arazisi genişliği 52.85 dekardır. İşletme gruplarında ortalama yerfıstığı arazisi 15.00 ile 112.74 da arasında değişmektedir. Toplam yerfıstığı ekim alanları, toplam işlenen arazinin \%35.98'lik kısmını oluşturmaktadır (Çizelge 1).

Araştırma bölgesinde yerfıstığı yetiştiriciliğinin ağırlıklı olarak I.ürün şeklinde olduğu belirlenmiştir. Nitekim incelenen işletmelerde
I.ürün olarak yetiştiriciliği yapılan yerfıstığı ekim alanları, toplam yerfıstığı ekili alanlarının \%70.71'ini oluşturmaktadır. II. ürün yerfıstığı ekili alanlarda ise bu oran \%29.29'dur (Çizelge 2.).

Araştırma yapılan alan içerisinde üreticiler tarafından üç çeşit yerfıstığı tohumu kullanıldığı belirlenmiştir. Bunlar üreticilerin Amerikan fıstık dedikleri NC-7 çeşidi, yerli fıstık dedikleri Çom çeşidi ve Halisbey çeşitleridir. Buna göre, işletmelerin yetiştirdikleri yerfıstığı çeşitlerinin oransal olarak dağılımı incelendiğinde $\% 90.00$ oranıyla NC-7 çeşidi ilk sırada yer alırken, $\% 6.00$ oranı ile Çom çeşidi ikinci sırada, \%4.00 oranı ile Halisbey çeşidi üçüncü sıradadır.

İncelenen işletmeler, ektikleri çeşidi seçme nedenlerine $\% 47.00$ oranında kaliteli olup piyasada tercih edildiği için, \%28.00 oranında alternatif tohum olmadığı için, \%14.00 oranında verimli olduğu için, \%7.00 oranında araştırdım, $\% 4.00$ oranında diğer sebepler cevapları vermişlerdir.

İncelenen işletmelerde ortalama olarak \%15.00 oranında sertifikalı tohum kullanılmaktadır. Bu oran birinci grup işletmelerde $\% 10.00$, ikinci grup işletmelerde $\% 24.14$ ve üçüncü grup işletmelerde $\% 12.90$ 'dır. Sertifikalı tohumluk kullanım oranı çok düşük olup, sertifikalı kaliteli tohum üretimindeki problemler çözülmeli ve kullanımının teşvik edilmesi sağlanmalıdır.

Çizelge 1. İşletmelerin arazi genişlikleri ve toplam yerfıstığı arazisinin işlenen alan içindeki payı

Table 1. Land assets of enterprises and percentage of peanut cultivation with regard to their total area

\begin{tabular}{|c|c|c|c|c|c|c|c|}
\hline \multirow[t]{2}{*}{ İşletme Grupları } & \multicolumn{2}{|c|}{ Toplam İşletme Arazisi } & \multicolumn{2}{|c|}{ Toplam İşlenen Alan (1) } & \multicolumn{2}{|c|}{$\begin{array}{l}\text { Toplam Yerfıstığı } \\
\text { Arazisi (2) }\end{array}$} & \multirow{2}{*}{$\begin{array}{c}\text { Oran } \\
(2 / 1)^{*} 100\end{array}$} \\
\hline & (da) & $\%$ & (da) & $\%$ & (da) & $\%$ & \\
\hline 1 & 63.19 & 19.60 & 79.00 & 21.51 & 15.00 & 11.35 & 18.99 \\
\hline 2 & 110.66 & 25.08 & 119.72 & 23.64 & 41.03 & 22.52 & 34.27 \\
\hline 3 & 228.29 & 55.32 & 259.87 & 54.85 & 112.74 & 66.13 & 43.38 \\
\hline Ortalama & 128.14 & 100.00 & 146.88 & 100.00 & 52.85 & 100.00 & 35.98 \\
\hline
\end{tabular}

Çizelge 2. İşletmelerin toplam yerfıstığı arazisi içinde I. ve II. ürünün payı Table 2. Percentage of first and second crop peanut cultivation of enterprises

\begin{tabular}{|c|c|c|c|c|c|c|}
\hline \multirow{2}{*}{$\begin{array}{l}\text { İşletme } \\
\text { Grupları }\end{array}$} & \multicolumn{2}{|c|}{ I. Ürün Yerfıstığı Arazisi } & \multicolumn{2}{|c|}{ II. Ürün Yerfıstığı Arazisi } & \multicolumn{2}{|c|}{ Toplam Yerfıstığı Arazis } \\
\hline & da & $\%$ & da & $\%$ & da & $\%$ \\
\hline 1 & 11.45 & 76.33 & 3.55 & 23.67 & 15.00 & 100.00 \\
\hline 2 & 36.00 & 87.74 & 5.03 & 12.26 & 41.03 & 100.00 \\
\hline 3 & 72.10 & 63.95 & 40.64 & 36.05 & 112.74 & 100.00 \\
\hline Ortalama & 37.37 & 70.71 & 15.48 & 29.29 & 52.85 & 100.00 \\
\hline
\end{tabular}


Çizelge 3. İşletmelerin kullandıkları yerfıstığı çeşitlerinin dağılımı (\%)

Table 3. Distrubiton of peanut varieties (\%) used by enterprises

\begin{tabular}{cllll}
\hline İşletme & \multicolumn{2}{l}{ Tohum Çeşidi } & & Toplam \\
\cline { 2 - 4 } Grupları & Çom & Halisbey & NC-7 & 100.00 \\
\hline 1 & 5.00 & 0.00 & 95.00 & 100.00 \\
2 & 6.90 & 6.90 & 86.20 & 100.00 \\
3 & 6.45 & 6.45 & 87.10 & 100.00 \\
Ortalama & 6.00 & 4.00 & 90.00 & 100 \\
\hline
\end{tabular}

Çizelge 4. İşletmelerde Yerfıstığı Üretiminde Uygulanan Gübre Çeşitlerinin Miktarı (kg/da)

Table 4. Amount of different fertilizer types ( $\mathrm{kg} / \mathrm{da}$ ) used by enterprises for peanut cultivation

\begin{tabular}{cccccccccc}
\hline $\begin{array}{c}\text { İşletme } \\
\text { Grupları }\end{array}$ & 20.20 .0 & $20.20+Z n$ & Üre & $\begin{array}{c}15.15 .15 \\
\text { \%26- } \\
33\end{array}$ & $\begin{array}{c}\text { A.S. } \\
\% 21\end{array}$ & $\begin{array}{c}\text { DAP } \\
\% 18.46\end{array}$ & 13.12 .24 & Toplam \\
\hline 1 & 10.25 & 0.00 & 5.50 & 8.50 & 14.50 & 1.88 & 2.88 & 0.00 & 43.51 \\
2 & 10.52 & 0.00 & 5.00 & 5.00 & 12.93 & 3.28 & 5.17 & 0.00 & 41.90 \\
3 & 4.52 & 0.65 & 4.84 & 8.23 & 12.58 & 3.55 & 7.42 & 0.81 & 42.60 \\
Ortalama & 8.55 & 0.20 & 5.15 & 7.40 & 13.45 & 2.80 & 4.95 & 0.25 & 42.75 \\
\hline
\end{tabular}

Çizelge 5. İşletmelerde yerfıstığı üretiminde uygulanan gübre çeşitlerinin dağılımı (\%)

Table 5. Distribution of different fertilizer types ( $\mathrm{kg} / \mathrm{da}$ ) used by enterprises for peanut cultivation

\begin{tabular}{cccccccccc}
\hline $\begin{array}{c}\text { İşletme } \\
\text { Grupları }\end{array}$ & 20.20 .0 & $20.20+z n$ & Üre & 15.15 .15 & $\begin{array}{c}\text { A.N. } \\
\% 26- \\
33\end{array}$ & $\begin{array}{c}\text { A.S. } \\
\% 21\end{array}$ & $\begin{array}{c}\text { DAP } \\
\% 18.46\end{array}$ & 13.12 .24 & Toplam \\
\hline 1 & 23.56 & 0.00 & 12.64 & 19.54 & 33.32 & 4.32 & 6.62 & 0.00 & 100.00 \\
2 & 25.11 & 0.00 & 11.93 & 11.93 & 30.86 & 7.83 & 12.34 & 0.00 & 100.00 \\
3 & 10.61 & 1.53 & 11.36 & 19.32 & 29.53 & 8.33 & 17.42 & 1.90 & 100.00 \\
Ortalama & 20.00 & 0.47 & 12.04 & 17.26 & 31.43 & 6.58 & 11.63 & 0.59 & 100.00 \\
\hline
\end{tabular}

Çizelge 6. İşletmelerin yerfıstığı üretiminde yaprak gübresi kullanım durumları Table 6. Leaf fertilizer usage of enterprises

\begin{tabular}{ccccccc}
\hline \multirow{2}{*}{$\begin{array}{c}\text { İşletme } \\
\text { Grupları }\end{array}$} & \multicolumn{2}{c}{$\begin{array}{c}\text { Yaprak Gübresi Kullanan } \\
\text { İşletme Sayısı }\end{array}$} & $\begin{array}{c}\text { Yaprak Gübresi } \\
\text { Kullanmayan İşletme } \\
\text { Sayısı }\end{array}$ & \multicolumn{2}{c}{ Toplam } \\
\cline { 2 - 7 } & Adet & $\%$ & Adet & $\%$ & Adet & $\%$ \\
\hline 1 & 27 & 67.50 & 13 & 32.50 & 40 & 100.00 \\
2 & 22 & 75.86 & 7 & 24.14 & 29 & 100.00 \\
3 & 26 & 83.87 & 5 & 16.13 & 31 & 100.00 \\
Ortalama & 75 & 75.00 & 25 & 25.00 & 100 & 100.00 \\
\hline
\end{tabular}

Çalışma kapsamında incelenen işletmelerin ortalama $\% 24.00$ oranında toprak tahlili yaptırdıkları belirlenmiştir. Birinci grup işletmelerde toprak tahlili yaptıran işletmeler $\% 17.50$ oranında, ikinci grup işletmelerde $\% 17.24$ oranında ve üçüncü grup işletmelerde \%38.71 oranındadır. Toprak tahlili yaptıran işletmelerin tamamı toprak tahlili sonucuna göre gübreleme yapmaktadır.

Anket sonuçlarına göre dekara ortalama gübre kullanımı $42.75 \mathrm{~kg}$ olarak bulunmuştur. İşletme grupları itibariyle gübre kullanımı $41.90 \mathrm{~kg}$ ile $43.51 \mathrm{~kg}$ arasında değişmektedir (Çizelge 4).

Inceleme neticesinde dekara kullanılan 42.75 kg gübrenin; \%31.43'ünü \%26 ve 33'lük A.Nitrat, \%20.00'sini kompoze (20-20-0), \%17.26'sını kompoze (15-15-15), \%12.04'ünü üre, \%11.63'ünü kompoze (18-46-0), \%6.58'ini A.Sülfat, \%0.59'unu kompoze (13-12-24) ve $\% 0.47$ 'sini kompoze (20-20+zn) oluşturmaktadır. Ortalama olarak en fazla $\% 26$ ve 33'lük amonyum nitrat gübre çeşidi kullanılırken, en az kompoze $(20-20+z n)$ çeşidi kullanılmaktadır (Çizelge 5).

Anket sonuçlarına göre, ortalama olarak dekara saf $10.63 \mathrm{~kg}$ azot $(\mathrm{N}), 5.17 \mathrm{~kg}$ fosfor $(\mathrm{P})$ ve $1.17 \mathrm{~kg}$ potasyum (K) kullanıldığı belirlenmiştir. İşletmelerin tamamı bakteri aşılması yapmadığını, uzun yıllardır yerfıstığı yetiştirdiklerini fakat yerfıstığı köklerinde nodül oluşumunu kontrol de etmediklerini belirtmişlerdir. İşletmelerin yerfıstığı üretiminde yaprak gübresi kullanım durumları çizelge 6.'de verilmiştir. 
Çizelge 7. Yerfıstığı tarımında en fazla şikayet edilen zararlılar Table 7.Most common pests of peanut cultivation

\begin{tabular}{|c|c|c|c|c|c|c|c|c|}
\hline \multirow{3}{*}{$\begin{array}{c}\text { Yerfıstığı Tarımında En } \\
\text { Fazla Hangi Zararlıdan } \\
\text { Şikayetçisiniz }\end{array}$} & \multicolumn{6}{|c|}{ İşletme Grupları } & \multirow{2}{*}{\multicolumn{2}{|c|}{ Ortalama }} \\
\hline & \multicolumn{2}{|c|}{1} & \multicolumn{2}{|c|}{2} & \multicolumn{2}{|c|}{3} & & \\
\hline & Adet & $\%$ & Adet & $\%$ & Adet & $\%$ & Adet & $\%$ \\
\hline Kırmızı Örümcek & 14 & 35.00 & 15 & 51.72 & 11 & 35.48 & 40 & 40.00 \\
\hline Yaprak Biti & 5 & 12.50 & 6 & 20.69 & 5 & 16.13 & 16 & 16.00 \\
\hline Yeşil Kurt & 18 & 45.00 & 5 & 17.24 & 10 & 32.26 & 33 & 33.00 \\
\hline Toprak Altı Zararlıları & 1 & 2.50 & 2 & 6.90 & 4 & 12.90 & 7 & 7.00 \\
\hline Prodenya & 2 & 5.00 & 1 & 3.45 & 1 & 3.23 & 4 & 4.00 \\
\hline Toplam & 40 & 100.00 & 29 & 100.00 & 31 & 100.00 & 100 & 100.00 \\
\hline
\end{tabular}

İncelenen işletmelerin tamamı kimyasal mücadele yapmaktadır. Kimyasal mücadeleye karar verirken ortalama olarak \%77.00'si hastalık ve zararlıyı gördüğünde, \%19.00'u uzman tavsiyesi ile ve \%4.00'ü ise hastalık ve zararlıların, zarar yapma seviyesine ulaşınca mücadele yaptıklarını belirtmişlerdir. Çalışma kapsamında yerfıstığı tarımında işletmelerin en fazla şikayet ettiği zararlılar çizelge 7.'de verilmiştir.

Yapılan çalışma kapsamında, yerfıstığı tarımında en fazla hangi hastalıktan şikayetçisiniz sorusuna verilen cevaplara göre, ortalama \%56.00 kök boğazı çürüklüğü, \%41.00'i sap çürüklüğü ve \%3.00 yaprak leke hastalığı verileri elde edilmiştir. İncelenen işletmelerin tamamı, ekim öncesi veya ekim sonrası çıkış öncesi yabancı ot ilaçlaması yapmaktadır. Çıkış sonrası yabancı otlara karşı kimyasal mücadele ortalama olarak $\% 62.00$ kullandıkları tespit edilmiştir.

\section{Sulama ve Bakım}

İncelenen işletmelerde, toplam 100 işletmenin tamamının sulama yaptığı belirlenmiştir. Sulama yapan işletmelerin ortalama \%67.00'si salma sulama, \%14.00'ü yağmurlama sulama ve $\% 19.00$ 'u salma ve yağmurlama sulama yöntemini birlikte kullanmışlardır. İşletmelerde damlama sulama sisteminin hiç kullanılmadığı, yağmurlama sulama yönteminin ise yeterli düzeyde olmadığı görülmüştür.Işletmelerin ortalama 15 gün ara ile 5 kez sulama yaptıkları tespit edilmiştir. Sulama çoğunlukla temmuz, ağustos ve eylül aylarında yapılmaktadır. Genel olarak ilk sulamanın çiçeklenme başlangıcında, bitkiler iyice susayıp karardıktan sonra haziran ayı sonu temmuz ayı başlangıcında, çiftçilerin deyimiyle bu tarlanın sahibi ölmüş noktasına gelince yapıldığı söylenebilir.
İşletmelerde çapalama işlemi; traktör çapası, boğaz doldurma ve el çapası şeklinde yapılmaktadır. Ayrıca yabancı otlarla mücadele için avlama şeklinde ot çekme işlemi gerçekleştirilmektedir. Traktör çapası, boğaz doldurma işlemi ile birlikte ortalama üç kez, el çapası bir kez yapılmakta ve sulamaların öncesinde avlama şeklinde ot çektirme işlemi yaptırılmaktadır. Bakım işlemlerinde, işletmeler hassas davranmakta gereken hassasiyeti göstermektedir.

\section{Hasat-Harman, Kurutma ve Verim}

İncelenen işletmelerde; harmanlama işleminin $\% 18.00$ oranında elle yapıldığı, \%82.00 oranında makine ile yapıldığı belirlenmiştir. Elle harmanlama işlemi yapılan işletmeler Düziçi ilçesindeki küçük ölçekli işletmelerdir. İşletme gruplarına göre; birinci grup işletmelerin, \%40.00'। harmanlama işlemini elle yapmakta, \%60.00'ı makine ile yapmaktadır. İkinci grup işletmelerin, \%6.90'ı harmanlama işlemini elle yaparken, \%93.10'u makine ile yapmaktadır. Üçün grup işletmelerde ise harmanlama işleminin tamamı makine ile yapılmaktadır.

Incelenen işletmelerde; ortalama $\% 38.00$ oranında yerfıstığı sapı hayvan yemi olarak kullanılmakta fazlası satımakta, \%33.00 oranında hayvan yemi olarak satılmakta, $\% 14.00$ oranında hayvan yemi olarak kullanılmakta, \%11.00 oranında hayvan yemi olarak kullanılmakta, hasat karşıı̆̆ olarak verilmekte ve $\% 4.00$ oranında hasat karşılığı olarak verilmektedir. Hasat karşılığı yerfıstığı sapını veren işletmeler; hasadı elle yaptıran 1.grup küçük ölçekli işletmelerdir.

İncelenen işletmelerde; birinci ve ikinci ürün yerfıstığının ortalama verimi $323.70 \mathrm{~kg} / \mathrm{da}$ 'dır. Birinci ürünlerde $341.38 \mathrm{~kg} / \mathrm{da}$, ikinci ürünlerde $281.00 \mathrm{~kg} / \mathrm{da}$ ortalama verim elde edilmiştir. 
İşletme gruplarına göre verimi inceleyecek olursak, birinci grup işletmelerde; birinci ve ikinci ürün ortalama verimi $313.25 \mathrm{~kg} / \mathrm{da}$ 'dır. Birinci ürünlerde $317.47 \mathrm{~kg} / \mathrm{da}$, ikinci ürünlerde $299.65 \mathrm{~kg} / \mathrm{da}$ olarak gerçekleşmiştir. İkinci grup işletmelerde; birinci ve ikinci ürün ortalama verimi $316.35 \mathrm{~kg} / \mathrm{da}$ 'dır. Birinci ürünlerde 323.95 $\mathrm{kg} / \mathrm{da}$, ikinci ürünlerde $262.05 \mathrm{~kg} / \mathrm{da}$ olarak gerçekleşmiştir. Üçüncü grup işletmelerde; birinci ve ikinci ürün ortalama verimi 327.99 kg/da'dır. Birinci ürünlerde 354.43 kg/da, ikinci ürünlerde $281.09 \mathrm{~kg} / \mathrm{da}$ olarak gerçekleşmiştir. İşletmecilerin, ortalama \%77'si yerfıstığı yerine ekilen üründen yüksek verim aldığını, \%14'ü buğday ekerse yüksek verim aldığını, \%8'i yüksek verim alamadığını ve $\% 1$ ' $\mathrm{i}$ de yerfıstığından başka ürün ekmediğini bildirmiştir.Incelenen işletmelerin 63 tanesi (\%63) depolama yapmakta ve 37 tanesi (\%37) depolama yapmamaktadır. Depolama yapmayan 3 işletme deposu bulunmasına rağmen depolama yapmadığını belirtmektedir. Depolama yapan 63 işletmenin, 19'u depoda ilaçlama yaparken(\%30), 44 tanesi $(\% 70)$ depoda ilaçlama yapmamaktadır.

İncelenen işletmelerde; 1 . ve 2 . ürün yerfıstığının ortalama olarak $2.30 \mathrm{TL} / \mathrm{Kg}$, 1.ürün yerfıstığının ortalama olarak $2.36 \mathrm{TL} / \mathrm{Kg}$, 2.ürün yerfıstığının 2.15 TL/Kg fiyat üzerinden satıldığı belirlenmiştir. İşletmeciler 2011 yılı üretim sezonunda ürettikleri yerfıstığını daha yüksek fiyattan tüccara sattıklarını belirtmişlerdir.

\section{İşletmelerde Yerfıstığı Üretiminde Karşılaşılan Sorunlar}

İşletmelerin \%49'u sulama maliyetinin yüksek, \%20'si suyun yetersiz olduğunu, \%12'si sulama konusunda sorun yaşamadıklarını, $\% 11$ 'i maliyetin yüksek ve suyun yetersiz olduğunu, \%4'ü mazotun pahalı olması nedeniyle sulama maliyetinin yüksek olduğunu, \%3'ü elektriğin pahalı olması nedeniyle sulama maliyetinin yüksek olduğunu ve $\% 1$ 'i de kanaletlerde bakım olmadığı için kanaletlerin kaldırmadığını belirtmişlerdir.

İşletmelerin \%54'ü hasat işleminde problem olmadığını belirtmiştir. \%38'i yağışlar nedeniyle zamanında hasat yapamadıklarını, \%3'ü hasat kayıplarının fazla olduğunu, \%2'si işçi bulmada sorun yaşadıklarını, \%1'i hasat ücretinin pahalı olduğunu, \%1'i kurutma problemi yaşadıklarını ve $\% 1 ' i$ işçi bulmada sorun yaşadıklarını, söküp çeviren makinenin kırsal kalkınma yatırımları kapsamında devlet tarafından desteklenmediğini belirtmişlerdir.
Ürünün pazarlanmasında; işletmelerin $\% 62$ 'si fiyatın düşük olduğunu, \%19'u problemlerinin olmadığını, \%9'u zaman zaman fiyatın düşük olduğunu, $\% 5$ 'i aracıların fazla olduğunu, \%3'ü tüccardan başka alıcı olmadığı için rekabetin olmadığını, \%1'i güvenilir tüccar bulunmadığını ve \%1'i de taşıma masraflarının yüksek olduğunu belirtmişlerdir.

\section{Sonuç}

Genel olarak değerlendirildiğinde işletmelerin \%56'sı yerfıstığı üretiminde, tohum kullanımıyla ilgili olarak sorunlarının olmadığını, $\% 24$ 'ü tohum fiyatının yüksek olduğunu, $\% 14$ 'ü kaliteli, sertifikalı tohum bulmakta zorlandıklarını, bulsalar da pahalı olduğunu ve \%6'sı da tohumluğu kendileri ayırdığı için sorun yaşamadıklarını belirtmişlerdir.

\section{Kaynaklar}

Arıoğlu H.H., 1999. Yağ Bitkileri Yetiştirme ve Islahı. Çukurova Üniversitesi Ziraat Fakültesi Ders Kitabı, Genel Yayın No: 220, Adana

Emeksiz F., 1994. Adana ilinde yerfıstığı üretilen işletmelerin üretimle ilgili bazı yapısal özellikleri. Çukurova Üniversitesi Ziraat Fakültesi Dergisi, 9(2): 17-32

Gıda, Tarım ve Hayvancılık Bakanlığı, Osmaniye İı Müdürlüğü, 2012 Yılı Çalışma Raporu

Gül A., Arıoğlu H., Tülücü K., Biçici M., Özgür F., Fenercioğlu H., 2001. Osmaniye'nin Simgesi: Yerfıstığı Ekonomisi, Üretim Tekniği, Hastalık ve Zararlıları, Gıda Sanayi Açısından Önemi. 1. Osmaniye Fıstık Festivali Etkinlikleri, Osmaniye Gazeteciler Cemiyeti Kültür Yayını, Sayı 1

Işık H., 2003. Türkiye'de Yerfıstığı Üretim Ekonomisi (Yüksek Lisans Tezi). Çukurova Üniversitesi, Fen Bilimleri Enstitüsü s. 104

Koca H., 2006. Yerfıstığı tarımı: imkanlar ve sorunlar. Doğu Coğrafya Dergisi/Eastern Geographical Review, Cilt 11, Sayı 16

Kurtay F., 1988. Adana İli, Osmaniye İlçesinde Yerfıstığı Yetiştiriciliği ile İlgili Üretici Sorunları. (Yüksek Lisans Tezi). Çukurova Üniversitesi, Fen Bilimleri Enstitüsü, s. 36

Parlakay O., 2011. Türkiye'de Yerfıstığı Tarımında Teknik ve Ekonomik Etkinlik (Doktora Tezi). Çukurova Üniversitesi, Fen Bilimleri Enstitüsü, s. 167

Taşkaya B., 2007. Yerfıstığı, Tarımsal Ekonomi Araştırma Enstitüsü Bakış, Sayı: 9, Nüsha: 7, Haziran 2007

TÜIK 2014. Türkiye İstatistik Kurumu Kayıtları. (http://www.tüik.gov.tr) (Erişim tarihi: 02.02.2014) 